\title{
Russell on Acquaintance with Spatial Properties: The Significance of James
}

\author{
Alexander Klein
}

\section{Introduction}

Russell's rejection of William James's pragmatism-one might say his revulsion-is widely known to most every philosophy student. So it might be surprising to find Russell writing in 1910 about the "great loss which philosophy has sustained" in James's death that year. James was "one of the most eminent, and probably the most widely known, of contemporary philosophers." Russell particularly emphasized the "high value of his [James's] work on psychology," an estimation Russell says is "universally admitted" (Russell 1992a, 286). Elsewhere, Russell expresses his "profound respect and personal esteem" for his recently deceased friend (Russell 1910, vi). Russell's high regard for James was longstanding. Writing to Lady
Ottoline Morrell in 1914, he would recall finding James the single

A. Klein (ه)

California State University Long Beach, MHB 9171250 Bellflower

e-mail: alexand Beach, CA 90840-2408, USA

oThe

S. Lapointer(s) 2017

Palgrave Innovation Pincock (eds.), Innovations in the History of Analytical Philosophy, 
most interesting person he had met during an early trip to America in $1896 .{ }^{1}$ Even late in life, Russell would say that the Harvard phi. losophy department was "the best in the world" up until James's death (Russell 1998/1967, 220), an especially remarkable comment com. ing from somebody who says he once believed that "everything worth knowing was known at Cambridge" (hint: he did not mean the one in Massachusetts; Russell 1998/1967, 135). Thus, despite his opposition to pragmatism, Russell's praise for James was significant and sustained.

Russell's sentiments may be less surprising to specialists, who will be familiar with his adoption of James's neutral monism in 1919, after having repeatedly and at some length criticized that position (starting in 1913; see Hatfield 2002b; Banks 2014; Eames 1989, 44, 143). But even specialists are unlikely to be familiar with Russell's reading of Jamess Principles of Psychology (1981/1890).

I will argue that some aspects of Russell's theory of perception-particularly in Our Knowledge of the External World (1914)-make more sense when viewed through the lens of James's masterpiece. Specifically, I will contend that Russell was actually a devotee of James's distinctive theory of spatial perception, and that grasping this helps shed light on the account of our acquaintance with spatial relations in OKEW. ${ }^{2}$ What is more, fleshing out this background of agreement helps clarify the wider epistemological differences between the two men.

I begin by arguing against the standard reading of OKEW as a work of foundationalist epistemology, paying special attention to the mistaken assumption that Russell thought we could know about the "facts of sense-perception" (OKEW, 53) with certainty. I then defend an alternative reading according to which that book's aim is to effect a reconciliation of the apparently disparate images we get from psychology and physics.

The question then becomes whether Russell actually engaged with the psychology and physics of his day, and in particular whether we can situate his views about perception with respect to the constellation of empirical theories available at the time. It turns out that he read James's Principles quite seriously, and this helps us understand which substantive psychological theories Russell might have thought needed to be reconciled with physics, and why. 
What is more, OKEW makes some controversial, unargued-for assumptions about the nature of spatial perception, assumptions that James had actually defended by means of experiment. So grasping James's influence also helps us see what evidence Russell might tacitly have relied on in arriving at those controversial assumptions from OKEW. I conclude by highlighting ways Russell's and James's more general approaches to perception ultimately diverged, however, and diverged in ways that finally put them at epistemological odds.

\section{Acquaintance and Foundationalism in Russell}

In OKEW, Russell seeks to portray entities like everyday objects, spatial points, and temporal moments as logical constructions out "the facts of sense (i.e., of our own sense-data)" (OKEW, 72). Why did he bother undertaking this project?

Scott Soames gives what I take to be the standard answer. "The aim" of Russell's external world program, he writes, "was to show how most of what we confidently take ourselves to know about the world is capable of being justified-and in fact is justified-in the face of skeptical doubt of the sort familiar since Descartes"(Soames 2014, 535-536).

Cartesian skepticism is usually thought to assert at least two things, per Peter Klein. It asserts (1) that all our beliefs about the external world are uncertain because we might be living in a universe that is both vastly different and yet indistinguishable from the one we ordinarily take ourselves to be in, such as in the evil demon scenario of "Meditation One." And it asserts (2) that if we cannot defeat (1) then we cannot have genuine knowledge about the external world (Klein 2015). ${ }^{3}$

Other than simply refusing to take this sort of skepticism seriously, philosophers have two broad strategies open to them for responding (Klein 1981, 3-4). The first is to argue against (1) and contend that at least some of our beliefs about the external world are indeed certain. A leading example of this strategy is foundationalism, which tries to establish that some beliefs are known non-inferentially and with certainty, 
and can provide a basis for justifying other beliefs, particularly those concerning the external world. The second strategy is to formulate a relatively weaker theory of knowledge according to which (2) is falsei.e., to formulate a theory (like reliabilism or pragmatism) that accepts that some measure of uncertainty is actually compatible with genuine knowledge.

If Russell is in fact responding to Cartesian skepticism, which kind of response is he offering? Soames and others take him to be pursuing roughly the first strategy. They point to Russell's so-called fundamental epistemological principle as establishing his own, empiricist brand of foundationalism. This principle says that "[e]very proposition which we can understand must be composed wholly of constituents with which we are acquainted" (Russell 1918-1910/1911, 219). Russell of course calls some of those objects of acquaintance "sense-data," and he is standardly depicted as regarding our knowledge of these things as certain (e.g., Irvine 1999, vol. III, xiii; Soames 2014, 538; Miah 2006, 56-59). Thus, when he logically constructs material bodies out of sense-data in OKEW, commentators have suggested that his intention is to undermine Cartesian skepticism (Pears 1981; Pears 1967, 15-16, 22-23, 58-59; Soames 2014, 535-536, Sainsbury 1979, 147-159) effectively by way of denying (1), above.

This foundationalist, anti-skeptical reading misrepresents Russell's views on our knowledge of our own sense-data and in turn the aims of his external world program at large. The assumption that Russell thinks we can know "the facts of sense" with certainty is false. And if we grant this unfortunate assumption, it is a short step to then (wrongly) construe the external world program as aimed at setting our knowledge of the external world on a skeptic-proof foundation via truth-preserving, deductive inferences.

It is true that, as (Savage 1989) has argued, there are some passages in POP that might be read as committing Russell to the certainty of acquaintance. But POP is a public lecture in which Russell often skates over careful distinctions for ease of presentation (by his own admission; Russell 1913, 76), and in his more technical work during the 1910s, Russell is careful not to portray acquaintance as furnishing us with infallible judgments about sense-data (see Savage 1989, 151-154). 
Some terminology is helpful here. Russell defines "sensation" as an act in which we are immediately acquainted with sense-data (POP, 17). And he uses "sense-data" to mean "the things that are immediately known in sensation: such things as colours, sounds, smells, hardnesses, roughnesses, and so on" (POP, 17). ${ }^{4} \mathrm{He}$ usually identifies sense-data by listing examples of what the early moderns called "secondary qualities," but it will be crucial to our story that Russell also regards some spatial and temporal relations as sense-data as well.

What is the epistemic standing of the "acquaintance" relation? Russell says that sensations cannot be mistaken about their data because sensory awareness involves a two-place relation between the sensational act and its object:

From the fact that presentation is a two-term relation, the question of truth or error cannot arise with regard to it: in any case of presentation there is a certain relation of an act to an object, and the question whether there is such an object cannot arise. In the case of judgment, error can arise; for although the several objects of the judgment cannot be illusory, they may not be related as the judgment believes that they are. The difference, in this respect, between judgment and presentation is due to the fact that judgment is a multiple relation, not a two-term relation. (my italics; Russell 1913, 76)

His thought is that when the acquaintance relation actually obtains between a sensation and a sense-datum, the sense-datum must exist, and so there is no possibility for error to arise. Now, one might think that if sensations cannot be mistaken, then sensations deliver truths with certainty. But this is not Russell's view-sensations cannot be mistaken, but they cannot be accurate either. He says that "the question of truth or error" cannot arise with respect to sensation, presumably because they are not doxastic states at all, but psychological acts tied in a merely causal way to sense-data. Of course, Russell thinks we can make judgments about sensation, but then (as with all judgments) the possibility of error very much arises. Unlike presentations, judgments involve multiple relations between the subject and a complex object. In such cases, each element contained in the proposition being judged must exist, but 
the relation that the judgment portrays those elements as standing into one another can be mistaken. ${ }^{5}$

It is worth considering a passage from Principia (1910) in which Russell also acknowledges our fallibility when we attempt to make judgments of sensation. (Note that Russell uses "perception" and "sensation" as synonyms, during this period. $)^{6}$

A judgment of perception, according to the above definition, must be true. This does not mean that, in a judgment which appears to be one of perception, we are sure of not being in error, since we may err in thinking that our judgment has really been derived merely by analysis of what was perceived. But if our judgment has been so derived, it must be true. (PM I, 45-46)

The passage from (Russell 1913) given above suggests that genuine judgments of sensation can be mistaken when the relations imputed by the judgment do not actually obtain. But this passage suggests that the possibility for error crops up only when we mistakenly take ourselves to be making a judgment of sensation. On either view, though, judgments of sensation cannot provide an indubitable foundation of the sort required by the foundationalist reading. According to one view, judgments of sensation can be, and sometimes are, mistaken. According to the other, genuine judgments of sensation cannot be mistaken, but we cannot be absolutely certain when we are making such a judgment. The effect is the same in either version-any judgment we take to be sensational is fallible. So just as sensations themselves cannot give us certain knowledge of the sort needed for a foundationalist epistemology, neither can judgments of sensation. I think we have good reason to reject the foundationalist, anti-skeptical reading of OKEW.

Foundationalist readers might respond by emphasizing the 1910 claim that a judgment "must be true" if it is genuinely about sensation, and they might insist that Russell thinks we are rarely or never mistaken about which of our judgments really is about sensation. But in OKEW. Russell repeatedly says that it is neither easy nor straightforward to figure out what, precisely, is given in sense experience. He claims the figure out what, precisely, is given in sense experience. He claims for
this is a matter we can only settle by doing empirical psychologt:
instance, he writes: 
Psychologists, however, have made us aware that what is actually given in sense is much less than most people would naturally suppose, and that much of what at first sight seems to be given is really inferred. ... When we hear a person speaking, our actual sensations usually miss a great deal of what he says, and we supply its place by unconscious inference; in a foreign language, where this process is more difficult, we find ourselves apparently grown deaf, requiring, for example, to be much nearer the stage at a theatre than would be necessary in our own country. ${ }^{7}$ Thus the first step in the analysis of data, namely, the discovery of what is really given in sense, is full of difficulty. (OKEW, 68-69)

Russell claims that we often think we directly perceive a sound (e.g., some spoken word in a play) when actually we have unconsciously inferred that sound from others we really did hear (like the other words in the sentence in which the first word occurred). Notice that figuring out which raw sense-data really form the basis of our experiences is not a matter of simple introspection, for Russell, but a task "full of difficulty," one to be left to empirical psychology. ${ }^{8}$ In other words, these judgments are fallible, and again, it is hard to believe he would see them as providing an epistemically perfect, skepticism-resistant foundation for our knowledge of the external world.

Foundationalist readers might grant that Russell saw judgments of sensation as fallible, but might insist that there is still something authoritative about Russellian sensations themselves-indeed, sensations produce what Russell is happy to call knowledge by an acquaintance, after all. So am I too quickly dismissing the prospect that sensations themselves, predoxastic states though they may be, might provide Russell with a bedrock for refuting Cartesian skepticism?

There are three points to make in response. First, the relationship between sensation and knowledge by acquaintance is not at all clear. Russell introduced the distinction between "knowledge by acquaintance" and "knowledge by description" in POP, Chap. 5. In a subsequent treatment, he says we get knowledge by acquaintance when (whenever?) we have a sensation (Russell 1913, 77). But it is unclear how sensations, which are not judgments, and not even truth-apt, can constitute knowledge at all. For a sensation to constitute knowledge, the sensation must 
have representational content. But representations, like truth claims, must afford at least some possibility of error, which again Russellian sensations do not.?

In a reply to OKEW to which I will return below, Dewey actually makes this very point, suggesting that sensation could not constitute knowledge (Dewey 1916, 285-286). Interestingly, in his response Russell tentatively concedes the point. All he needs in OKEW, Russell says, is that perceptions produce data that are "the basis for our knowledge of the world. This is enough for the present; the question of the cognitive status of perceptions need not concern us" (Russell 1919, 23, $1986,152)$. Clearly, Russell cannot think perceptions (or sensations) provide a "basis" in the sense of constituting simple bits of infallible knowledge from which our complex knowledge of the world is inferred, in the fashion of foundationalism.

He does not spell out the precise sense in which sensation does provide a "basis" for knowledge, unfortunately, and I submit that it is considerably more difficult than has been supposed to figure out what he has in mind. I cannot offer a more detailed treatment of this issue here, and nothing in my positive reading of Russell turns on it. However, for the objection under consideration to be made compelling, we would at least need an account of how Russellian sensations could produce genuine knowledge. But such an account is elusive.

Second, that Russell intended to appeal to sensations in an anti-skeptical argument is dubious given that OKEW only mentions the threat of skepticism to dismiss it as not worth taking seriously. ${ }^{10}$ Russell says such skepticism is "logically irrefutable" (OKEW, 67) and should be set aside and ignored-philosophy must "examine and purify our common knowledge" without pretending it has access to some "superfine brand of knowledge" (OKEW, 66) that can ground a rational response to the skeptic. So Russell is clear that the results of logically constructing material bodies out of sense-data in OKEW do not achieve-and do not seek to achieve-an infallible bulwark against external world skepticism (also see OKEW, 71). ${ }^{11}$ So again, the objection seems misplaced.

Finally, the objection does get something right, admittedly. Russell does think we (somehow) know "the facts of sense" with high confdence, as he clearly places those facts among our "hard data." But the 
objection suggests that Russell is showing how to take the further step of inferring the existence of a material world from our own sense-data. $\mathrm{He}$ explicitly says this is what he is not doing. OKEW seeks to portray "the world of physics as a construction rather than an inference" (vi), in Russell's words. What is the difference between the two?

Russell's "supreme maxim in scientific philosophizing," which first appears in "The Relation of Sense-Data to Physics" (also published in 1914), helps elucidate this distinction: "Wherever possible, logical constructions are to be substituted for inferred entities" (Russell 1986, 11). This is a maxim for interpreting propositions that contain references to "inferred entities" like material bodies that persist in space and time, even when unobserved. We are to define these in terms of "less hypothetical entities" like occurrent sense-data, wherever possible. This is logical construction, a process that lets us "obtain a new and less doubtful interpretation of the body of propositions in question" (Russell 1986, 12). In contrast, Russell thinks entities like persisting material bodies are only inferred in the sense that they are not directly experienced, but postulated in an inference to the best explanation for the stability of our sense-data.

It is true that Russell calls interpretations whose inferred entities have been replaced by logical constructions "less doubtful." So perhaps Russellian constructions (rather than inferences) give us certain or at least highly secure knowledge of the external world.

But this is a misleading way to understand logical construction. In OKEW, Russell is at pains to deny that logical construction itself licenses any declarations about how the world must be. He writes:

The function of logic in philosophy, as I shall try to show at a later stage, is all-important; but I do not think its function is that which it has in the classical tradition. In that tradition, logic becomes constructive through negation. Where a number of alternatives seem, at first sight, to be equally possible, logic is made to condemn all of them except one, and that one is then pronounced to be realised in the actual world. Thus the world is constructed by means of logic, with little or no appeal to concrete experience. The true function of logic is, in my opinion, exactly the opposite of this. As applied to matters of experience, it is analytic 
rather than constructive [in the traditional sense]; taken a priori, it shows the possibility of hitherto unsuspected alternatives more often than the impossibility of alternatives which seemed prima facie possible. Thus, while it liberates imagination as to what the world may be, it refuses to legislate as to what the world is.(OKEW, 8)

Russell seems to have Hegel and his followers principally in mind as philosophers who try to reach substantive, metaphysical truths by making inferences from supposedly indisputable premises. Hegel tries to infer substantive facts about what the universe must be like by using subject-predicate logic to eliminate, for example, real spatial and temporal relations from the universe (OKEW, 49). Russell of course wants to replace the old subject-predicate logic, and he wants to apply logic to what we experience, not to metaphysical principles (OKEW, 38). But it is crucial that he also wants to reposition the role of logic in philosophy so that it no longer pretends to deliver indubitable truths about the external world. Instead, Russell wants to use logic to "liberate the imagination" by broadening the set of hypotheses about the world we know to be consistent with the facts about which we take ourselves to be most confident, including the "facts of sense" in particular. ${ }^{12}$

But just because we can consistently interpret statements about material bodies in terms of statements about sense-data-which is what the construction project of OKEW would establish, if successful-it does not follow (as anti-skeptical readers suppose) that material bodies really exist, or that they really are nothing but sense-data. We should therefore not be surprised that Russell repeatedly refers to his construction of the physical world as "hypothetical" (OKEW, 93, 96, 97). He does not think his logical constructions establish the existence of the external world with anti-skeptical certainty; logical construction shows us only what "may be," not what must be. This is a problem for the anti-skeptical reading of OKEW.

So if the External World program is not intended as a bulwark against external world skepticism, just what does Russell hope to accomplish? As we will see in Section 3, Russell's construction of the external world out of the facts of sense offers us one possible interpretation of physics that would be consistent with the facts of psychology. 


\section{3 \\ The Reconciliationist Reading}

Russell repeatedly claims that the central accomplishment of Our Knowledge is to have helped resolve conceptual tensions between physics and psychology, as Christopher Pincock and Omar Nasim have both emphasized. ${ }^{13}$ The point of logically constructing physical entities out of what is given in sensation, for Russell, is not to refute external world skepticism, but rather to show that the fundamental concepts of moden physics and psychology are in fact logically compatible. The idea is to show that one common framework can accommodate basic terms and principles of the two sciences.

Here are some relevant passages. Russell describes a "discrepancy between the world of physics and the world of sense," a discrepancy he promises to show to be "more apparent than real" (OKEW, 64-65). He says he is going to demonstrate this by constructing the world of physics out of basic elements of the world of sense. Thus, after taking some preliminary steps in this direction, he writes: "The world we have constructed can, with a certain amount of trouble, be used to interpret the crude facts of sense, the facts of physics, and the facts of physiology" (OKEW, 92-93). A few pages later he writes that

Our hypothetical construction ... shows that the account of the world given by common sense and physical science can be interpreted in a way which is logically unobjectionable, and finds a place for all the data, both hard and soft. It is this hypothetical construction, with its reconciliation of psychology and physics, which is the chief outcome of our discussion. (my italics, OKEW, 97)

These are strong words - "the chief outcome" of Russell's construction is to have accomplished a "reconciliation of psychology and physics." 14

As Pincock points out, Russell's interest in reconciling physics and "psychology persists at least through the 1920s. For instance, in 1915's "On the Ultimate Constituents of Matter," Russell writes: "it is only when physical 'things' have been dissected into series of classes of particulars, as we have done, that the conflict between the point of view of 
physics and the point of view of psychology can be overcome" (Russell 1986, 86). ${ }^{15}$ And in AMi (1921), we find the following:

This book has grown out of an attempt to harmonize two different tendencies, one in psychology, the other in physics, with both of which I find myself in sympathy, although at first sight they may seem inconsistent. (AMi, xvii)

In this later book, the chief issue is that Russell sees behaviorists as moving toward a material conception of mind, while physicists are challenging the traditional conception of matter. Neutral monism is his attempt to show how to bring these two tendencies into harmony. Similar concerns persist in his 1927 Outline of Philosophy (Russell 1960/1927, 2). Thus, Russell's comments in Our Knowledge about the need to reconcile physics and psychology are not just passing remarks, but reflect a consistent theme in his philosophy during this era.

Let us review some basics concerning Russell's construction. He characterizes the data with which his project begins as "matters of common knowledge" (OKEW, 65). This includes our "acquaintance with particular objects of daily life" such as tables, turnips, and so on; our knowledge of distant people, places, and events we gain through history, geography, news, and such; and "the systematization of all this knowledge of particulars by means of physical science" (OKEW, 66).

According to Russell, we quickly notice that the data of common knowledge can be divided into primitive and derivative beliefs. Primitive beliefs are those that we subscribe to "on their own account," while derivative beliefs are "inferred," in one of the two senses. A belief is said to be logically derivative when it is based on a conscious inference. For instance, when I form a belief about the result of some arithmetic calculation, my belief is logically derivative. Beliefs caused not by an explicit inference but by some other belief are said to be psychologically derivative. Think of forming a belief about a square table's real shape on the basis of the trapezoidal image it projects on the retina-such cases of "unconscious inference" (as Helmholtz had called them) produce psychologically derivative beliefs. 
Russell calls beliefs that are psychologically derivative, but logically primitive "soft data" because "our confidence in their truth tends to diminish the more we think about them" (OKEW, 70). Examples include our belief that tables and turnips continue to exist even when we do not perceive them. In contrast, Russell calls "hard data" those beliefs that tend to resist the "solvent influence of critical reflection" (OKEW, 70). So the project of logical construction is to recast talk about some set of dubious soft data in terms of more secure hard data.

As Russell contemplates this construction, however, he introduces familiar problems of perspective. When we walk around the table, what is psychologically primitive-our sense-data themselves-change shape, yet we do not think the "real" table changes. So before he can construct medium-sized physical objects out of sense-data, Russell first needs to construct some kind of stable, spatial framework (OKEW, 84), a project to which he ends up devoting the core of the book.

We can already see why Russell claims that the "chief outcome" of his discussion is the "reconciliation of psychology and physics" (OKEW, 97). The soft data that get constructed in his external world program include the world of physics - the world of material bodies that persist in a common spatio-temporal framework. And the basis of this construction is that which is "psychologically primitive"-that which the best psychological research tells us is actually given in sense. Thus, the success or failure of this construction project turns not on whether the foundation is infallible or certain in some anti-skeptical sense. Instead, if Russell can show how to construct physical bodies and their spatiotemporal framework from a psychological basis, he will have shown that the disparate worlds of physics and psychology are logically compatible.

Now, one obstacle to establishing this reading may be that Russell cites little actual psychological research in OKEW. So can Russell really have been serious about reconciling the latest work in psychology and physics if he did not actually engage the latest work in psychology and physics? 


\section{Historical Evidence: Russell on James's Psychology}

Whatever else he might have read on the subject, we do know that James's Principles of Psychology (1890) was an important source for Russell. Frances Brennan and Nicholas Griffin have recently reprinted Russell's marginalia in his copy of the Principles (Brennan and Griffin 1997-1998). There are 450 marginalia throughout Russell's copy, and the chapter that is most dense with markings is James's "Perception of Space" chapter.

Brennan and Griffin note that Russell called the Principles "by far the most delightful and readable book on the subject" (Brennan and Griffin 1997-1998, 123; Russell 1992a, 268). He read it once in its entirety as a student and then read the second volume (including the material on space) again in 1895 as he was getting ready to submit his dissertation on geometry. ${ }^{16}$

Brennan and Griffin cite letters that suggest that Russell relied on the Principles for his dissertation chapter entitled "Psychological Origin of Space-relations." That chapter has not survived, unfortunately, and it is not included in Essay on the Foundations of Geometry. But his dissertation generally attempted "to isolate the purely a priori in geometry from the purely empirical," Brennan and Griffin say (Brennan and Griffin 1997-1998, 128). This is an issue that connects up both with James's own work on space (Klein 2009) and with the later concerns of OKEW.

Russell's marginalia in his copy of the Principles do not by themselves establish whether Russell actually endorsed James's views on spatial perception. But Brennan and Griffin do write that "Russell's marginalia concentrate overwhelmingly on three topics: James's treatment of spatial relations, and of the three-dimensionality and measurability of space" (Brennan and Griffin 1997-1998, 130). In Sect. 5, we shall see that these concerns (especially the first) are all revisited in OKEW, so the focus of these marginalia fits nicely with our claim that James's theory is an important psychological source for that work.

Finally, Brennan and Griffin cite a late letter in which Russell does explicitly endorse James's theory of spatial perception. The letter was 
written in May of 1954 and was addressed to the art connoisseur Bernard Berenson's biographer. Russell writes that he thought Berenson was "under a misapprehension in following Berkeley's mistaken theory of vision. I put B. B. on to William James's Psychology to dissuade him from this view" (Brennan and Griffin 1997-1998, 131). That is strong evidence that Russell was in fact favorably inclined toward James's unique theory of spatial perception.

\section{$5 \quad$ Hard Data: Russell's Two Remarkable Assumptions}

So how does James's work on space actually inform OKEW? I will now pick out two important claims that Russell makes about where exactly the line is to be drawn between hard and soft perceptual data. The claims would have been controversial to many psychologists of the era. Russell therefore might be suspected of having relied on unwarranted assumptions about perception, were it not for the fact that James had offered a battery of empirical evidence in support of precisely these claims, and offered that evidence in portions of the Principles we know Russell to have read very carefully.

\section{First Assumption: Some Spatial Relations Are Given}

Russell makes a few idiosyncratic claims about what kinds of spatial properties are given in sensation-especially in visual sensation. The first assumption is this: he holds that some spatial relations are psychologically primitive.

For the present, however, let us confine ourselves to the hard data, with a view to discovering what sort of world can be constructed by their means alone.

Our data now are primarily the facts of sense (i.e. of our own sense-data) and the laws of logic. But even the severest scrutiny will allow some additions to this slender stock. Some facts of memory-especially of recent 
memory - seem to have the highest degree of certainty. Some introspective facts are as certain as any facts of sense. And facts of sense themselves must, for our present purposes, be interpreted with a certain latitude. Spatial and temporal relations must sometimes be included, for example in the case of a swift motion falling wholly within the specious present. And some facts of comparison, such as the likeness or unlikeness of two shades of colour, are certainly to be included among hard data. (my underline; OKEW, 71-72)

The "specious present" is a phrase James popularized in his work on temporal perception in the Principles (PP 573; see Andersen and Grush 2009) - it refers to the presently experienced moment, which James thinks always has some duration. ${ }^{17}$ What interests me about this passage is that it suggests that for Russell, an apparent motion that occurs inside the specious present introduces some spatial relations as part of the hard data of sensation. For instance, a perception of the relation between two apparent positions that a swiftly moving object traverses would be a psychologically primitive spatial relation, for Russell.

A critic might read the passage as ambiguous about whether Russell is saying that spatial and temporal relations are part of the hard data of sense because they are psychologically primitive, or whether he is rather saying that spatial and temporal relations are part of the hard data of sense even though they are not (strictly speaking) psychologically primitive. Consider Russell's claim that "even the severest scrutiny will allow some additions to this slender stock." The phrase "slender stock" clearly refers to "the facts of sense" and to "the laws of logic" - two key members of the set of hard data. Now, suppose that by "facts of sense" Russell simply means "psychologically primitive data." Then, one natural reading is that the psychologically primitive data do not exhaust the set of hard psychological data; so the "additions" (including spatial and temporal relations) would be other data that are not psychologically primitive, yet still deserve to be counted as hard data of sense. This reading would be incompatible with my view since I am taking Russell to be asserting that some spatial relations are hard data because they are psychologically primitive. 
My reading of this passage is that Russell understands the "facts of sense" to make up only an incomplete subset of the set of primitive psychological data, so that what needs to be added are (in some cases) other psychological data that are not, strictly speaking, "facts of sense," yet are still to be regarded as psychologically primitive.

A nearby passage adds credence to my reading, where Russell suggests that spatial relations in both two and probably even three dimensions are given in raw sensation (OKEW, 73). ${ }^{18}$ What is more, in a later work Russell leaves no doubt that he thinks some spatial relations are given in perception: " $[t]$ here is a spatial relation between two parts of the same visual field, or between two simultaneous pin-pricks on different parts of the hand; such spatial relations are within the realm of sensation, and are not learnt by experience" (my italics; Russell 2013/1948, 235-236).

\section{Second Assumption: Spatial Points Are not Given}

I mentioned that Russell is going to construct the space of physics out of sense-data. To be precise, he distinguishes between what he calls the "private space" of each person's perspective and the one, enveloping "perspective space." The latter is an ordered set that has each private space as an "element" (OKEW, 89-90). Russell proposes to construct perspective space (which stands in for the physical universe) out of sense-data that appear in our private spaces.

What is interesting is that Russell insists not only on constructing the one "perspective space" that houses all material bodies in the universe. We must also construct spatial points, since these are at once crucial to physics, and yet not given in sensation. That is to say that Russell not only tries to construct spatial points in perspective space-he tries to construct spatial points even in private space (OKEW, 113-115). This is Russell's second remarkable assumption-that visual and tactile points are actually psychologically derivative, not primitive.

Russell writes:

Another respect in which the spaces of immediate experience differ from the space of geometry and physics is in regard to points. The space of 
geometry and physics consists of an infinite number of points, but no one has ever seen or touched a point. If there are points in a sensible space,
they must be an inference. (OKEW, 113-114)

Russell goes on to offer a procedure for "showing how points might be [logically] manufactured from sense-data," a procedure Whitehead originally developed. What is curious is why Russell thinks sensory points need to be "manufactured" at all.

Let me add that Russell concludes his construction of points by returning to the gulf between psychology and physics. He says his construction of points in space (and instants in time) is meant to show

the kind of way in which, given a world with the kind of properties that psychologists find in the world of sense, it may be possible, by means of purely logical constructions, to make it amenable to mathematical treatment by defining series or classes of sense-data which can be called respectively particles, points, and instants. If such constructions are possible, then mathematical physics is applicable to the real world, in spite of the fact that its particles, points, and instants are not to be found among actually existing entities.(OKEW, 122)

Again, notice Russell's emphasis on showing how the world of continuous sense-data, as that world is described by psychologists, can be reconciled with the world of discrete spatio-temporal points described by physics. This need for what turns out to be a fairly tricky construction of points in perspective space arises because Russell takes there to be no psychologically primitive sensations that are punctiform in a way that might easily be mapped onto points or instants in space or time. The denial of punctiform sensations turns out to be another substantive psychological assumption on Russell's part, as we will see below. 


\section{A Brief History of Theories of Spatial Perception}

In order to situate these two assumptions in the context of the psychology of Russell's day, I will now consider two psychological traditions in broad outline. One is the associationist psychology that dominated the British scene from the time of Hartley and Hume. The other is the nineteenth-century tradition of German experimentalism whose results were widely discussed, digested, and revised even in the Englishspeaking world. James stands out against the background of both these traditions because he treats spatial relations as psychologically primitive and spatial points as (in a sense) psychologically derivative-seemingly in keeping with Russell's perceptual assumptions as discussed above.

One can think of Berkeley's New Theory of Vision as a key source for British associationism. Berkeley introduces the claim that the visual and tactile sensory fields are fundamentally composed of what he calls minima sensibilia - these are visual and tactile atoms that are meant to be the invariant building blocks of our complex perceptions (Berkeley 1871/1709, \$\$54, 62, 80-83, 86). Minima visibilia are colored points that, like pixels, constitute our visual field, and minima tangibilia are pin-prick-like feelings that constitute our tactile field. Berkeley seeks to explain how we learn to perceive distance by correlating visual with tangible sensibilia. ${ }^{20}$

Hume takes on board the idea of minima sensibilia, especially in his discussion of spatial perception in Book I, part ii of the Treatise (Hume 1978/1739, I.ii.1, 27). He also sets an important constraint on acceptable explanations of spatial perception: explanations of how the mind produces ideas of space and extension should proceed from sensory building blocks that are not themselves spatial. ${ }^{21}$

For Hume, minima sensibilia-our sensory building blocks-are simple perceptions since (by definition) they cannot be subdivided. But all perceptions of extension can be subdivided, for Hume, and hence they are complex (Hume 1978/1739, I.ii.3, 38). So minima sensibilia must themselves be unextended, and our spatial perceptions arise when we relate collections of these extensionless minima sensibilia, Hume 
argues. Many commentators have found Hume's account to be wanting because a mind that "relates" minima sensibilia would seem to need an antecedent grasp of spatial relations, even if the sensibilia themselves are unextended.

There is an instructive contrast here with Russell, who writes that "no one has ever seen or touched a point" (OKEW, 113). Hume disagrees, insisting that extensionless points really are visible. He offers a simple procedure for helping us isolate an actual impression of a minima visibilium. The procedure involves putting a spot of ink on a piece of paper and then retiring to a distance from which the spot is just barely visible (Hume 1978/1739, I.ii.1, 27).

In the nineteenth century, Thomas Brown, both James and John Stuart Mill, and Bain all retain the notion that we gain spatial ideas by associating the originally unextended building blocks of sensation. ${ }^{21} \mathrm{We}$ also find Thomas Huxley endorsing Berkeley's classical notion of minima sensibilia in 1873 (Huxley 1873, 344-345).

Meanwhile, experimental psychology was exploding in Germany. In that context, a fundamental division in approaches to spatial perception-between nativist and empirist accounts - traces back to an argument between Hering and Helmholtz. ${ }^{22}$ By the time Russell wrote, this division had become canonical in articles, textbooks, and histories of psychology written in or translated into English. ${ }^{23}$

Here is a nutshell account of the division. Helmholtz had advocated what he called an "empirist" (empiristich) explanation of spatial perception. He held that raw sensation does not include spatial information. We must learn to perceive spatial relations; what is given in sensation is just a collection of discrete, non-spatial points. We then make unconscious inferences about spatial location and distance on the basis of these originally non-spatial ingredients. ${ }^{24}$

This is typically thought to be an update of Lotze's view. Helmholtz himself wrote that for Lotze, "to the sensations from spatially distinct nerve endings correspond various determinate local signs [Localzeichen], whose spatial meaning is learned." 25 In the local sign tradition, the vis ual and tactile sensory fields are conceived of as pixelated, and at least in this respect, it resembles the associationist tradition. Helmholtz argues 
that we must learn to interpret the pixels as representing spatial locations and relation.

Helmholtz's main rival on spatial perception is another local sign theorist, Ewald Hering. Hering holds that the points of our visual and tactile fields are actually given with native spatial values. Every point in the visual field is supposed natively to have a three-place positional value. One value gives us the sensation's position on a left-right axis in the visual field; another value gives us the sensation's position along an up-down axis; and a third gives us the position on a near-far axis. Thus, Hering writes:

There are only three simple spatial feelings and, correspondingly, three systems of spatial relations for the doubled retina. The first simple spatial feeling corresponds to the ability to perceive height, the second to the ability to perceive breadth, and the third to the ability to perceive depth. They are all elicited by every retinal point. (quoted in translation at Herrnstein and Boring 1965, 149)

Notice the tendency among local sign theorists to slip back and forth between talk about "retinal point[s]"-purely physical entities-and talk about "simple spatial feelings." The key thing to emphasize is that on both sides of the controversy, German psychologists were largely committed to atomistic theories-to theories according to which the sensory fields involved in spatial perception (typically sight and touch) are composed of collections of sensory points.

Again, it is not only German psychologists who held such a view; associationists also understood minima sensibilia to be unextended sensory points. So from the perspective of either tradition, Russell's second assumption-that sensory points in private space are not given, but need to be constructed-looks controversial and unsupported.

What is more, what I called Russell's "first assumption," that some spatial relations are psychologically primitive, also fits poorly with both traditions. Since local sign theorists see raw sensation as non-spatial, they clearly cannot accept that spatial relations are in any sense psychologically primitive. ${ }^{26}$ The same goes for associationists. 
Two Germans would come to break with this atomistic tradition in psychology-Ernst Mach and Carl Stumpf. But the key heretic for our story is their mutual friend and ally in America, William James. In one sense, James sides with Hering in the German controversy. He thinks spatial properties, including some positions, shapes, and relations, are given in sensation and not learned. But in another crucial sense, James profoundly departs from both Hering and Helmholtz.

In both the local sign tradition and associationism, what is given is a collection of individual, atomic sensations; the debate is then over what kinds of properties these atomic sensations are given with, and what properties must be inferred. For instance, do atomic sensations come equipped, as it were, with positional values? Or must the position of a stimulus in some way be inferred on the basis of experience?

In contrast, James rejects any atomistic conception of the visual and tactile fields. He holds that what is psychologically "primitive" in vision is what he calls a vague, "teeming muchness" (James 1879, 67). Thus, in his earliest article on spatial perception, he writes:

The spatial quale is, then, primitively a very vague quantum, but it is a spatial quantum. ... The vaguely spatial field of vision is made clear and distinct by being subdivided. To subdivide it means to have the attention called now to one point, now to another within its limits and upon its borders. (James 1879, 70)

James does think we have to learn to see spatially-but only in the sense that we must learn to pick out distinct points inside a visual (and tactile) field that is primitively spatial. ${ }^{27}$ Thus, for James, much like for Russell, the perception of distinct points is a problem that demands an explanation, not a simple fact about what is given in sensation.

James supports his claim that the visual and tactile fields are not composed of minima visibilia with experimental evidence. For instance, consider what psychologists call a "two-point discrimination" task, in which a subject is blindfolded and asked to tell when her skin is being impressed by two compass points and when it is being impressed by one. As the compass points are moved closer together, subjects lose the ability reliably to distinguish between the two cases. James notices 
that if you change the experiment and ask when a compass point is stationary and when it is moving across the skin, subjects reliably identify motion over patches of skin that are $1 / 10^{\text {th }}$ the size of the smallest patches of skin in which they are reliably able to perform the two-point discrimination. He thinks this shows that the perception of motionwhich is indubitably spatial-cannot be built out of a prior perception of points, since we do not have the ability to distinguish points inside the area in which we feel motion (PP, 810; James 1879, 73). In other words, James thinks our perception of extension cannot be built out of a prior perception of points. ${ }^{28}$

These experiments help support Russell's claim that spatial points are not psychologically primitive. What is more, James also takes these results to support the view that spatial relations are in some sense psychologically primitive. ${ }^{29}$ Thus, in the Principles he writes that spatial relations "are of the same order with the facts they relate" (PP, 149). Hence, "[r]ightness and leftness, upness and downness, are again pure sensations..." (PP, 150).

I think it is clear that there is a special harmony between James's account of spatial perception and Russell's claims about this topic in OKEW. ${ }^{30}$ From Berkeley to Bain, and from Lotze to Hering and Helmholtz, the perception of spatial points was traditionally not regarded as a problem to be explained. Far and away the standard view had been that unextended points are simply given in our raw visual and tactile sensations. If Russell were drawing on that tradition, it is unclear why spatial points would need to be constructed at all. What needs to be explained, for these figures, is how subjects manage to knit all these distinct points together, as it were, into organized perceptual fields. But the explanatory task moves very much in the opposite direction, for James and for Russell. What is given is the whole visual or tactile field at some particular time, they think. What needs to be explained is how subjects come to identify distinct points inside those sensory fields. 


\section{The Given?}

Our Knowledge of the External World was drawn from public lec. tures Russell delivered in Boston during an extended visit at Harvard in 1914. Given how heated the debate over pragmatism had already become, it is no surprise that some in his American audience were hostile. In particular, John Dewey criticized Russell along some lines that bear directly on my account.

Dewey contends that Russell's account of acquaintance is out of step with contemporary psychological research—especially with James's results:

I am on matter-of-fact ground when I point out that the assumption that even infancy begins with such highly discriminated particulars as those enumerated is not only highly dubious but has been challenged by eminent psychologists. According to Mr. James, for example, the original datum is large but confused, and specific sensible qualities represent the result of discriminations. In this case, the elementary data, instead of being primitive empirical data, are the last terms, the limits, of the discriminations we have been able to make. That knowledge grows from a confusedly experienced external world to a world experienced as ordered and specified would then be the teaching of psychological science, but at no point would the mind be confronted with the problem of inferring a world. (Dewey 1916, 298-299)

I have been arguing that Russell apparently draws on James's work in psychology. Have I overstated this point? According to Dewey, the Jamesean view of a confused "original datum" is in tension with Russell's idea of discrete sense-data with which we are acquainted.

But what does Dewey mean by "original datum"? Perhaps, he means that James postulates a "blooming, buzzing confusion" as a develop" mentally original sense-datum, in the sense that the infant's experience is originally vague and confused, but that the adult's experience cons tains discrete objects that are "the result of discriminations" she has learned to make over her lifetime. If this is Dewey's meaning, then the is right about James (see PP, 462-463), but wrong that James's view ${ }^{\text {is }}$ 
incompatible with Russell's. For when Russell talks about discrete sensedata that are "psychologically primitive," I see no evidence that he intends what is developmentally primitive. Rather, he means to distinguish the elements actually given in an adult, occurrent perception from those that the mind adds through psychological processing. This is processing of the sort Helmholtz calls unconscious inference, or what Stout calls "ideal constructions" (see Nasim 2012, 1171-1172).

In fact, Russell says as much in his response. "When I speak of 'data', more particularly of 'hard data', I am not thinking of those objects which constitute data to children or monkeys: I am thinking of the objects which seem data to a trained scientific observer" (Russell 1919, 7, 1986, 136, quoted at Nasim 2012, 1176). Nasim takes this as evidence that Russell is largely drawing from Stout's psychology, and not James's, but it might simply be that Russell and Dewey differed in their respective readings of James.

In any case, the issue between Dewey and Russell actually points to a deeper sense in which the latter may fairly be accused of misappropriating James. Consider another interpretation of what Dewey might mean by saying that the Jamesean "original datum" is obscure and confused. He might mean that we can distinguish a raw sensory core inside the full-blown, fully processed perceptions we actually experience. For instance, we think each retina transduces only a two-dimensional optic array into a neural signal. Somewhere along the way, that two-dimensional signal gets converted into a perception of our visual environment that is in three dimensions. Some psychologists (like Helmholtz) think that there is a two-dimensional sensation that is literally a core experiential part of our three-dimensional visual perception. Is Dewey saying that the "blooming, buzzing confusion" is an "original datum" of perceptual experience in this second way? In other words, is he saying that for James the vague and undifferentiated experience corresponds to the raw materials of adult perception?

Hopefully, this is not Dewey's reading of James, for it is not accurate; my concern is that it might be Russell's. James in fact denies that we can distinguish any core part of our occurrent perceptual experiences that can be regarded as having been purely "given" by the senses. He insists that any synthesizing or enriching of what might be regarded as 
raw sensory inputs (such as the filling-in of the blind spot in the visual field) takes place at the brain level. Genuinely, mental states are unities, James thinks. They are not "composed" of anything worth calling mental parts. ${ }^{31}$ We can in some sense recover the baby's experience of a "teeming muchness" when we meditate or take nitrous oxide, James thinks. But when we do so we are switching between different mental states, not looking "deeper" into some one state that is somehow both highly articulated and thoroughly vague at the same time.

Why think Russell holds that there is a "sensory core" to our occurrent perceptual states? For one thing, Russell writes about what "[p] sychologists" think is "actually given in sense" (OKEW, 68). The word "given" as it is used here has a psychological sense-it indicates a core part of an occurrent mental state that is purely caused by sensory inputs. This is precisely what distinguishes that which is "psychologically primitive" from that which is "logically primitive," for Russell. The latter category covers beliefs we take (rightly or wrongly) to be noninferential.

And in fact, for ease of exposition I have been writing all along as though James thinks spatial relations are "given" in raw sensation. But now I have to kick out the ladder. Spatial relations are "given," for James, in the sense that every other aspect of an occurrent perception is given. For James insists that no mental state "has any mode of being whatever except a certain way of being felt at the moment of being present" (PP, 174). In other words, he thinks all mental states have exactly the properties they seem to have, no more and no less.

But sensory-core accounts of perception are committed to denying this truism (as James takes it to be). For the sensory-core theorist must say that there is some sense in which my visual perception of the world is flat even though it looks three dimensional, or that my visual field in normal conditions is in fact donut shaped even though it does not appear that way. James claims that this amounts to denying "the logical principle of identity in psychology" (PP, 175), which he takes to have intolerably high costs (Klein Forthcoming).

So if I am right that Russell is drawing on James when he regards spatial relations (and not spatial points) as part of what is psychologically 
primitive, does Russell understand that which is psychologically primitive in a way that is nevertheless illicit by James's lights?

I think the answer may be yes, and the disagreement between the two men here is instructive about their ultimately diverging epistemologies. Consider that Russell does see epistemological implications for declaring some data to be psychologically primitive. For he thinks we have good reason to regard as part of our hard data any belief that is psychologically primitive. I have tried to distance Russell from foundationalism. The hard data do not consist of infallible beliefs, but only beliefs that are relatively secure in that they resist "the solvent influence of critical reflection." Still, what is relatively most epistemically secure, according to Russell, crucially includes beliefs that are directly caused by raw sensory input. James cannot accept this point.

Like most any philosopher, James accepts that some beliefs are more secure than others. But he does not accept that there is a sensory core, so he cannot say that the more secure beliefs are (or include as an identifiable part) those that stem from "pure" sensory acquaintance. ${ }^{32}$ Russell can gerrymander two districts inside a new experience-one constituting the primitive, sensory core with which our beliefs must agree and the other constituting the psychologically derivative. (Again, Russell does not recommend drawing this distinction through simple introspection but through laborious, empirical psychological research, which is fallible.) In contrast, James thinks this distinction is not just difficult to draw, but incoherent. We must always treat each experience as an inviolable whole.

Because James denies that any sub-feature of whole mental states has causal priority over others, he must also deny that any sub-feature of whole mental states has epistemic priority over others. In other words, James cannot style truth as a term-for-term correspondence between judgment parts and experience parts. This is why he maintains that the good fit that obtains between true beliefs and new experience must be a good fit "in the long run and on the whole" (James 1975/1907, 106).

So what should we say about Russell's appropriation of James's psychology, finally? Russell apparently read the Principles with a special focus on spatial perception, and I have shown that what he found was a view that fit the exigencies of his external world program very neatly. 
But it should come as no surprise that Russell cannot be regarded as a committed devotee of every part of James's psychology. Indeed, we find a more basic disagreement between the two when we get to the question of whether any components of occurrent mental states can be regarded as pure sensory products.

The intertwined intellectual relationship between Russell and James should remind us that lines of influence often do not respect the tidy boundaries of our creation myths. The psychology that emanates from the United States at the turn of the last century informs both pragmatism and early analytic philosophy, even if somebody like Russell draws different lessons than people like, say, Dewey or C. I. Lewis or even Roderick Firth (e.g., Lewis 1930, 1933; Firth 1949, 1950).

Accordingly, we should be wary of isolationist accounts of early analytic philosophy. Such accounts simply presuppose fundamental divisions between schools. But the clearest and most interesting disputes are often built atop a bedrock of considerable agreement. That is just what we find in the case of Russell and James.

\section{Notes}

1. Letter to Lady Ottoline Morrell, April 20, 1914 (Russell 1992b, 505).

2. Reference policy: $\mathrm{AMi}=$ (Russell 1995/1921); OKEW $=($ Russell 1914); PLA = (Russell 2010/1918); PM = (Whitehead and Russell 1910); POP $=($ Russell 1912); $\mathrm{PP}=($ James 1981/1890).

3. I am characterizing what I take most philosophers today to have in mind when they talk about overcoming Cartesian skepticism; I make no historical claim about the nature of Descartes's actual project.

4. I have to bracket the vexed question of whether during this period Russell regards sense-data as mental or physical. On this issue, see Russell's 1915 letter to The Journal of Philosophy, Psychology, and Scientific Methods, which is reprinted along with a helpful introduction in (Nasim 2009).

5. Note that the passage quoted was published in 1913; later that year, Russell would abandon his so-called multiple relations theory of judgment (Griffin 1985). But I have found no evidence that he dropped the distinction under discussion-namely, between sensations, which 
are psychological acts that are not truth-apt, and judgments of sensation, which are both truth-apt and liable to error-in the short time that would elapse before his 1914 OKEW.

6. Russell says he uses the word "'perception' ... as synonymous with 'sensation,' since I cannot observe any occurrence intermediate between sensation and judgment" (Russell 1913, 80).

7. Russell is perhaps drawing on James, who had employed the same example at (PP, 741n).

8. Russell expressly allows cases where we might be acquainted with some object without being certain that we are acquainted with the object. For instance, at (POP, 78) he says he is uncertain about whether he is acquainted with his own self: "The question whether we are also acquainted with our bare selves, as opposed to particular thoughts and feelings, is a very difficult one, upon which it would be rash to speak positively."

9. Indeed, at OKEW, 144-145, Russell seems to back away from applying the appellation "knowledge" to acquaintance at all, preferring to distinguish between "acquaintance" (simpliciter) and "knowledge about." Incidentally, Russell's vocabulary here recalls James's 1890 distinction between "knowledge of acquaintance" and "knowledge about" (see PP, 216-217).

10. Grayling rightly rejects the anti-skeptical reading of Russell's external world program, but wrongly takes Russell to see epistemology not as justificatory but rather as "a descriptive enterprise aimed at explaining the fact (which he did not question) that finite subjects attain scientific knowledge" (Grayling 2003, 452). If my reading in Section 3 is correct, then the project does have an important justificatory dimension, viz., to eliminate potential contradictions between physics and psychology that might vitiate theories in either field.

11. PLA is sometimes also regarded as Russell's attempt to flesh out the sort of foundationalist project some people think they find in OKEW. But in PLA Russell again rejects the notion that we can gain certainty in philosophy (PLA, 145, 150) - so he must reject that our philosophical constructions of material bodies out of sense-data are certain.

12. He elsewhere emphasizes the same point. By helping us make logical constructions, "[m]odern logic ... has the effect of enlarging our abstract imagination, and providing an infinite number of possible 
hypotheses to be applied in the analysis of any complex fact" (OKEW,
58 ).

13. My discussion in this section is particularly indebted to Pincock's work (Pincock 2006, 2008). I am grateful for personal correspondence with him on OKEW. After my own paper was drafted, I found an excellent article by Nasim that defends the reconciliationist reading in far more detail than I can afford here and locates Russell's reconciliationist pro. ject in a rich and then-lively tradition stretching back at least to the nineteenth century; see (Nasim 2012).

14. For other passages that express this theme, see (OKEW, 21, 101).

15. The Russell passages quoted in this and the next paragraph are all cited by (Pincock 2006).

16. The following year Russell actually stayed with the James's on a visit to the USA. The two men originally met through Russell's first wife, Alys Pearsall Smith, an American from a well-connected family (Russell 1967/1998, 69, 205).

17. Russell acknowledges his debt to James's conception of the specious present in (Russell 1915, 225). This is a point that Eames emphasizes (Eames 1989, 197, 1986).

18. "It seems probable that distances, provided they are not too great, are actually given more or less roughly in sight" (OKEW, 73). The qualifier "seems probable" is not surprising, given that Russell thinks it a matter of fallible, empirical psychological research to determine what elements really are psychologically primitive, as we saw in Section 2. And as I will argue in Section 6, psychologists in Russell's day disagreed about whether spatial relations-particularly distance relations-were really given in sensation.

19. Some commentators think Berkeley believed that raw visual sensation is composed of an organized, two-dimensional array of minima visibilia, while some think Berkeley sought to construct even the twodimensional visual array; for a discussion, see (Falkenstein 1994). An example of somebody who thinks Berkeley sought to construct even the two-dimensional visual array is (Grush 2007).

20. This constraint comes to be widely accepted among empirist spatial theorists in the German tradition, such as Lotze; see (Hatfield 1991, 161).

21. At any rate, this is William James's reading of the historical situationsee (PP, 901-902). 
22. For brief overviews of the empirism/nativism controversy in German psychology, see (Hatfield 1991, Appendix A, Pastore 1971, 159-164).

23. For example, see (Angell 1904/1906, $141 \mathrm{ff}$., Klemm 1914, Ch. 11). For a discussion of the German controversy from a distinctly Anglo perspective, see (Sully 1878a, b).

24. The classic source for Helmholtz's empirist view of spatial perception is (Helmholtz 1856-1867/2005, vol. III, \$26); for a discussion, see (Hatfield 1991, 202 and passim), and for a discussion of the notion of unconscious inferences in general, see (Hatfield 2002a).

25. Quoted in translation in (Patton 2014). Also see (Hatfield 1991, 158) for the view that local signs "accompany the sensations of color that arise from the stimulation of any given retinal point ..."

26. What I say here applies to empirist local sign theorists like Lotze and Helmholtz. Perhaps nativists like Hering could accept that some spatial relations are psychologically primitive. Still, I take Hering to advocate an atomistic conception of raw sensation that fits awkwardly at best with Russell's assumption that spatial points are not psychologically primitive.

27. James thinks the sensory fields are primitively spatial even in the third dimension; see (James 1879, 71).

28. I discuss these experiments in detail in (Klein 2009).

29. James says that spatial relations are part of the "teeming muchness" in the way a statue is part of the block of stone before the sculptor sets to work. We use attention to carve out some particular spatial relation (such as the distance between my coffee cup and the table edge) in something like the way the sculptor exposes a hand or a head in the stone (PP, 277).

30. Mach, Stumpf, and James Ward all portrayed themselves as James's allies when it came to spatial perception. Further research into the historical sources for Russell's views on perception would no doubt have to examine the influence of these figures as well (particularly Ward), but I cannot attempt such a task here.

31. For a more detailed discussion of this issue in James, see (Klein Forthcoming).

32. Perhaps, this helps explain his preference for holism (e.g., at James 1975/1907, 34-35). 
Acknowlegments I am grateful to the US-UK Fulbright Commission, which provided financial support while I was finishing this paper. I am also grateful for helpful feedback on an earlier draft from the editors.

\section{References}

Andersen, Holly K., and Rick Grush. 2009. "A Brief History of TimeConsciousness: Historical Precursors to James and Husserl." Journal of the History of Philosophy 47(2): 277-307.

Angell, James Rowland. 1904/1906. Psychology: An Introductory Study of the Structure and Function of Human Consciousness. 3rd ed. New York: Holt.

Banks, Erik C. 2014. The Realistic Empiricism of Mach, James, and Russell: Neutral Monism Reconsidered. New York: Cambridge University Press.

Berkeley, George. 1709/1871. "An Essay Towards a New Theory of Vision." In The Works of George Berkeley, ed. Alexander Campbell Fraser, 25-112. Oxford: Clarendon Press.

Brennan, Frances, and Nicholas Griffin. 1997-1998. "Russell's Marginalia in His Copy of William James's "Principles of Psychology"." Russell 17(2): 123-170.

Dewey, John. 1916. Essays in Experimental Logic. Chicago: University of Chicago Press.

Eames, Elizabeth R. 1986. "Russell and the Experience of Time." Philosophy and Phenomenological Research 46(4): 681-682.

Eames, Elizabeth R. 1989. Bertrand Russell's Dialogue with His Contemporaries. Carbondale: Southern Illinois University Press.

Falkenstein, Lorne G. 1994. "Intuition and Construction in Berkeley's Account of Visual Space." Journal of the History of Philosophy 32(1): 63-84.

Firth, Roderick. 1949. "Sense-Data and the Percept Theory, Part I." Mind 58(232): 434-465.

- 1950. "Sense-Data and the Percept Theory, Part II." Mind 59(233): $35-56$.

Grayling, A. C. 2003. "Russell, Experience, and the Roots of Science." In The Cambridge Companion to Bertrand Russell, ed. Nicholas Griffin, 449-474. Cambridge: Cambridge University Press.

Griffin, Nicholas. 1985. "Russell's Multiple Relation Theory of Judgment." Philosophical Studies 47(2): 213-248. 
Grush, Rick. 2007. "Berkeley and the Spatiality of Vision." Journal of the History of Philosophy 45(3): 413-442.

Hatfield, Gary C. 1991. The Natural and the Normative: Theories of Spatial Perception from Kant to Helmholtz. Cambridge: MIT Press.

- 2002a. "Perception as Unconscious Inference." In Perception and the Physical World: Psychological and Philosophical Issues in Perception, ed. Dieter Heyer, 115-143. Chichester: Wiley.

- 2002b. "Sense-Data and the Philosophy of Mind: Russell, James, and Mach." Principia: Revista Internacional de Epistemologia 6(2): 203-230.

Helmholtz, Hermann von. 1856-1867/2005. Treatise on Physiological Optics.

Trans. James Powell Cooke Southall. 3 vols. New York: Dover.

Herrnstein, Richard J., and Edwin Garrigues Boring. 1965. A Source Book in the History of Psychology. Cambridge: Harvard University Press.

Hume, David. 1739/1978. A Treatise of Human Nature; Being an Attempt to Introduce the Experimental Method of Reasoning into Moral Subjects. E. L. A. Selby-Bigge and P. H. Nidditch. 2nd ed. Oxford: Clarendon Press.

Huxley, Thomas Henry. 1873. "Bishop Berkeley on the Metaphysics of Sensation." In Critiques and Addresses, 320-350. London: Macmillan.

Irvine, A. D. 1999. Bertrand Russell: Critical Assessments. 4 vols. London: Routledge.

James, William. 1879. "The Spatial Quale." The Journal of Speculative Philosophy 13: 64-87.

- 1890/1981. The Principles of Psychology. In The Works of William James, Ed. Frederick H. Burkhardt, Fredson Bowers and Ignas K. Skrupskelis. Cambridge: Harvard University Press.

- 1907/1975. Pragmatism. Edited by Fredson Bowers and Ignas K. Skrupskelis, The Works of William James. Cambridge, MA: Harvard University Press.

Klein, Alexander. 2009. "On Hume on Space: Green's Attack, James's Empirical Response." Journal of the History of Philosophy 47(3): 415-449.

- Forthcoming. "The Death of Consciousness?" In Consciousness, ed. Alison Simmons. Oxford University Press.

Klein, Peter D. 1981. Certainty, a Refutation of Scepticism. Minneapolis: University of Minnesota Press.

Klein, Peter. 2015. "Skepticism." In The Stanford Encyclopedia of Philosophy, ed. Edward N. Zalta, (Summer 2015). Accessed August 29, 2016. http://plato. stanford.edu/archives/sum2015/entries/skepticism/. 

Klemm, Otto. 1914. A History of Psychology. Trans. Emil Carl Wilm and
Rudolf Pintner. New York: C. Scribner's Sons.

Lewis, Clarence Irving. 1930. "Pragmatism and Current Thought." Journal of Philosophy 27(9): 238-246.

- 1933. "Experience and Meaning." Proceedings and Addresses of the American Philosophical Association 7: 125-146.

Miah, Sajahan. 2006. Russell's Theory of Perception, 1905-1919. London: Continuum.

Nasim, Omar W. 2009. "Russell's July 1915 Letter on Sense-Data." The Bertrand Russell Society Quarterly 142-144: 35-38.

-. 2012. "The Spaces of Knowledge: Bertrand Russell, Logical Construction, and the Classification of the Sciences." British Journal for the History of Philosophy 20(6):1163-1182.

Pastore, Nicholas. 1971. Selective History of Theories of Visual Perception: 1650 1950. New York: Oxford University Press.

Patton, Lydia. 2014 (Fall Edition). "Hermann von Helmholtz," The Stanford Encyclopedia of Philosophy, ed. Edward N. Zalta. URL=http://plato.stanford.edu/archives/fall2014/entries/hermann-helmholtz/ $\swarrow$

Pears, D. F. 1967. Bertrand Russell and the British Tradition in Philosophy. New York: Random House.

Pears, David. 1981. "The Function of Acquaintance in Russell's Philosophy." Synthese 46(2): 149-166.

Pincock, Christopher. 2006. “The Scientific Basis for Russell's External World Program." Sixth Congress of HOPOS, Paris.

- 2008. "Carnap, Russell and the External World." In The Cambridge Companion to Carnap, ed. Michael Friedman and Richard Creath. Cambridge: Cambridge University Press.

Russell, Bertrand. 1910. Philosophical Essays. London: Longmans, Green.

— 1910-1911/1918. "Knowledge by Acquaintance and Knowledge by Description." In Mysticism and Logic: And Other Essays, 209-232. London: George Allen \& Unwin.

- 1912. The Problems of Philosophy. New York: Henry Holt.

- 1913. "The Nature of Sense-Data: A Reply to Dr. Dawes Hicks." Mind 22(85): 76-81.

-1914. Our Knowledge of the External World as a Field for Scientific Method in Philosophy. Chicago: Open Court.

- 1915. "On the Experience of Time." The Monist 25(2):212-233.

- 1918/2010. The Philosophy of Logical Atomism. London: Routledge. 
—. 1919. "Professor Dewey's "Essays in Experimental Logic"." The Journal of Philosophy, Psychology and Scientific Methods 16(1): 5-26.

. 1921/1995. The Analysis of Mind. London: Routledge.

-1927/1960. An Outline of Philosophy. New York: Meridian Books.

-1948/2013. Human Knowledge: Its Scope and Limits. London: Routledge.

1967/1998. Autobiography. London: Routledge.

. 1986. The Collected Papers of Bertrand Russell. In Vol. 8. ed. John G. Slater. London: George Allen \& Unwin.

-1992a. Logical and Philosophical Papers, 1909-13. In The Collected Papers of Bertrand Russell, Vol. 6. ed. John G. Slater and Bernd Frohmann. London: Routledge.

1992b. The Selected Letters of Bertrand Russell. In The private years, 1884-1914, Vol. 1, ed. Nicholas Griffin. London: Allen Lane.

Sainsbury, R. M. 1979. Russell, Arguments of the Philosophers. London: Routledge.

Savage, C. Wade. 1989. "Sense-Data in Russell's Theories of Knowledge." In Rereading Russell Essays in Bertrand Russell's Metaphysics and Epistemology, ed. C. Wade Savage and C. Anthony Anderson, 138-168. Minneapolis: University of Minnesota Press.

Soames, Scott. 2014. The Analytic Tradition in Philosophy. Vol. 1: The Founding Giants. Princeton: Princeton University Press.

Sully, James. 1878a. "The Question of Visual Perception in Germany (I)." Mind 3 (9): 1-23.

-1878b. "The Question of Visual Perception in Germany (II)." Mind 3 (10): 167-195.

Whitehead, Alfred North, and Bertrand Russell. 1910. Principia Mathematica. 3 vols. Cambridge: Cambridge University Press. 